\title{
As orações introduzidas por "incluso si" no espanhol sob a abordagem discursivo-funcional
}

DOI: http://dx.doi.org/10.21165/el.v49i2.2635

\author{
Talita Storti Garcia' \\ Bárbara Ribeiro Fante ${ }^{2}$
}

\section{Resumo}

Este trabalho investiga as orações introduzidas por incluso si no espanhol peninsular escrito, concebidas como híbridas na literatura porque, de acordo com diferentes compêndios, mesclam características tanto das condicionais quanto das concessivas. 0 objetivo da presente pesquisa é investigar as propriedades funcionais dessas estruturas sob o aparato teórico da Gramática Discursivo-Funcional a fim de determinar o nível e a camada de atuação dessas relações sob a hipótese de que incluso constitui uma partícula que assinala ênfase. O córpus utilizado é o CREA - Corpus de Referencia del Español Actual, banco de dados disponível on-line que conta com textos de diferentes gêneros, tanto da modalidade falada quanto da modalidade escrita. Os dados mostram que as orações prefaciadas por incluso si tendem a se estabelecer nas camadas mais altas do Nível Interpessoal e Representacional, quando desempenham função semântica condição, função retórica concessão ou ainda função interacional adendo. Esse resultado sugere-nos um novo olhar para o fenômeno em análise, apresentado pela literatura como gradiente, mas concebido neste estudo de forma discreta, em termos de funções.

Palavras-chave: incluso si; concessivo-condicionais; funcionalismo; Gramática Discursivo-Funcional.

1 Universidade Estadual Paulista "Júlio de Mesquita Filho" (UNESP), São José do Rio Preto, São Paulo, Brasil; talita.garcia@unesp.br; https://orcid.org/0000-0001-8695-6086

2 Universidade Estadual Paulista "Júlio de Mesquita Filho" (UNESP), São José do Rio Preto, São Paulo, Brasil; barbararfante@gmail.com; https://orcid.org/0000-0003-3063-3127 


\section{Las oraciones introducidas por incluso si en el español a la luz de la teoría de la gramática discursivo-funcional}

\section{Resumen}

Este trabajo investiga las oraciones introducidas por incluso si en el español peninsular escrito, comprendidas como híbridas en la literatura porque, según diferentes compendios, mezclan características tanto de oraciones condicionales como de oraciones concesivas. El objetivo de la presente investigación es analizar las propiedades funcionales de esas estructuras a la luz de la teoría de la Gramática Discursivo-Funcional a fin de determinar el nivel y el estrato de actuación de esas relaciones bajo la hipótesis de que incluso constituye una partícula escalar de énfasis. El corpus utilizado es el CREA - Corpus de Referencia del Español Actual - banco de datos disponible en línea que está compuesto de textos de diferentes géneros, en lengua hablada y en lengua escrita. Los datos enseñan que las oraciones introducidas por incluso si se establecen en los estratos más altos del Nivel Interpersonal y Representativo, cuando desempeñan función semántica condición, función retórica concesión o función interactiva 'adenda'. Ese resultado sugiere una nueva perspectiva del fenómeno en análisis, presentado por la literatura como escalar, pero concebido en ese estudio de forma discreta, en términos de función.

Palavras clave: incluso si; condicionales-concesivas; funcionalismo; Gramática Discursivo-Funcional.

\section{Introdução ${ }^{3}$}

As orações prefaciadas por incluso si são reconhecidas na literatura no rol das concessivo-condicionais (ou condicionais-concessivas4). Para Montolío (1999), quando incluso acompanha a conjunção si, constitui uma locução conjuntiva, ou seja, um bloco indissociável. As estruturas oracionais introduzidas por incluso si são concebidas por Flamenco García (1999) como concessivo-condicionais, reconhecidas também em outras línguas por autores como König $(1985,1986)$ no inglês, Haspelmath e König (1998) em estudos tipológicos e Neves (1999) no português. Todos eles admitem que as concessivo-condicionais caracterizam-se pelo hibridismo porque, para eles, mesclam características tanto das concessivas como das condicionais. Defendem que, com as

\footnotetext{
3 Os resultados deste artigo são advindos da dissertação de Mestrado intitulada As orações prefaciadas por 'incluso si' no espanhol escrito peninsular à luz da Gramática Discursivo-Funcional, defendida em agosto de 2018 na UNESP/São José do Rio Preto.

4 Em consonância com Flamenco García (1999), autor que aborda essas construções no espanhol, adotamos a nomenclatura concessivo-condicionais.
} 
concessivas, compartilham a quebra de expectativa5; com as condicionais, por sua vez, compartilham o sentido hipotético ${ }^{6}$.

Considerando essas propriedades, três grupos distintos são estabelecidos na literatura: (i) concessivo-condicionais universais, em que a oração subordinada é integrada por um quantificador universal; (ii) concessivo-condicionais alternativas, em que a oração subordinada é integrada por uma disjunção; e (iii) concessivo-condicionais escalares, em que a oração subordinada é integrada por uma partícula escalar, sob a qual recai o foco de interesse do presente trabalho.

As orações concessivo-condicionais escalares apresentam elementos que trazem a noção de escalaridade, pois o papel dessas orações é o de estabelecer seu escopo em um ponto mais alto de uma escala de possibilidades. Para Flamenco García (1999), o falante, ao usar uma construção concessivo-condicional de natureza escalar, introduz a informação com o valor que considera mais forte, ou seja, aquele valor que supostamente impediria o cumprimento do afirmado na oração principal, para, ao mesmo tempo, descartá-lo, conforme mostra a ocorrência ${ }^{7}$ (1) a seguir:

(1) -Si el PP convocara elecciones a corto plazo, el PSOE está preparado para darle respuesta?

-Incluso si las convoca ya, no nos van a pillar desprevenidos.

(1997, 9, Política)

-Se o PP convocasse eleições a curto prazo, o PSOE estaria preparado para dar uma resposta?

-Mesmo se convocasse já, não nos pegaria desprevenidos.

Em (1), a oração incluso si las convoca ya apresenta o ponto mais alto de uma escala de possibilidades (as eleições serem convocadas de última hora), uma objeção hipotética com relação à possibilidade de serem "pegos de surpresa", pois é consensual que uma convocação de última hora poderia pegar os candidatos desprevenidos.

5 Por delimitação do objeto de estudo, não trataremos das orações concessivas. Sobre esse assunto, ver König (1994), Haspelmath e König (1998), Crevels (1998), Zamproneo (1998), Mizuno (2007), Rosário (2012) e Garcia (2013).

6 Por delimitação do objeto de estudo, não trataremos das orações condicionais. Sobre esse assunto, ver Montolío (1999), Neves (1999), Oliveira (2008), Oliveira (2012) e Oliveira e Hirata-Vale (2016).

7 Todas as ocorrências serão seguidas da tradução livre para o português. 
Tendo em vista essa ideia de escalaridade hipotética e a quebra de expectativa engendrada nesse tipo de construção, o objetivo deste trabalho é investigar, à luz da Gramática Discursivo-Funcional, as propriedades funcionais das orações prefaciadas por incluso si em dados do espanhol peninsular sob a hipótese de que a partícula incluso constitui um operador de ênfase. Para isso, pretendemos verificar como se dá a atuação dessas orações de acordo com os níveis e camadas da Gramática Discursivo-Funcional (HENGEVELD; MACKENZIE, 2008) e pretendemos discutir o hibridismo postulado pela literatura, já que o modelo tende a apresentar uma concepção mais discreta dos fenômenos linguísticos.

O universo de investigação consiste em 69 ocorrências extraídas de textos da modalidade escrita do CREA (Corpus de Referencia del Español Actual), um banco de dados bastante diversificado, que oferece textos das modalidades falada e escrita de língua espanhola, tanto da América quanto da Espanha. A opção pelo espanhol peninsular escrito devese ao fato de que, nessa variedade e modalidade, os casos de orações prefaciadas por incluso si é muito mais recorrente do que no espanhol hispano-americano falado.

Este trabalho organiza-se da seguinte maneira: na seção (1) abordamos os principais conceitos da teoria base da presente pesquisa - a Gramática Discursivo-Funcional (HENGEVELD; MACKENZIE, 2008) para a compreensão da análise dos dados. Na seção (2) restringimo-nos a algumas considerações do que diz à literatura sobre as orações introduzidas por incluso si. Na seção (3), apresentamos os resultados advindos desta pesquisa sob a perspectiva discursivo-funcional, tendo como fator norteador a camada de atuação das construções prefaciadas por incluso si. Por fim, apresentamos, nas Conclusões, as principais contribuições deste estudo.

\section{O modelo da Gramática Discursivo-Funcional}

A Gramática Discursivo-Funcional (doravante GDF) é uma teoria que leva em conta a natureza da comunicação, procurando fornecer uma explicação da relação entre linguagem e contexto. A teoria é vista como um modelo de interação verbal cujo Componente Gramatical se une aos componentes Conceitual, Contextual e de Saída. Os três últimos componentes interagem com o Componente Gramatical por meio de operações de formulação (regras que determinam qual constituinte será válido nas representações semânticas e pragmáticas subjacentes) e de codificação (regras que convertem as representações semânticas e pragmáticas em representações morfológicas e fonológicas).

O Componente Gramatical se divide em quatro níveis de organização linguística: o Interpessoal (relacionado à pragmática) e o Representacional (relacionado à semântica) 
- responsáveis pelo processo de formulação ${ }^{8}$ - o Morfossintático (relacionado à morfossintaxe) e o Fonológico (relacionado à fonologia) - encarregados do processo de codificação. Todos esses níveis são impulsionados por um conjunto de primitivos e se organizam internamente em estratos hierárquicos.

O Nível Interpessoal, segundo Hengeveld e Mackenzie (2012), captura toda a formulação das distinções relativas à interação entre o Falante e o Ouvinte ${ }^{9}$. É organizado hierarquicamente pelas camadas seguintes: Movimento (M), Ato Discursivo (A) e Conteúdo Comunicado (C). Esse nível se refere aos aspectos pragmáticos da unidade da língua que refletem o papel da interação Falante-Ouvinte. Esses papéis se analisam em termos de funções retóricas e pragmáticas. Dentre as funções retóricas encontram-se: Motivação, Orientação, Correção, Aposição e Concessão (cf. PEZATTI; CAMACHO, 2017). Essas funções referem-se às formas em que os componentes do discurso são organizados pelo falante, a fim de alcançar seu propósito comunicativo, e também se relacionam às propriedades formais de um comunicado que influenciam o Ouvinte a aceitar o que diz o Falante. A Concessão para a GDF, portanto, é uma Função Retórica no Nível Interpessoal, em outras palavras, trata-se de uma relação de dependência entre dois Atos Discursivos (A), um Nuclear (Ai) e outro Subsidiário (Aj), sendo que esse último deve ser entendido como uma estratégia de que dispõe o Falante para alcançar seu objetivo comunicativo.

O Nível Representacional, por sua vez, refere-se aos aspectos semânticos da unidade linguística. Enquanto o Nível Interpessoal evoca algo, o Nível Representacional é responsável pela designação. Por isso, a utilização do termo semântica se relaciona aos meios pelos quais uma língua lida com os mundos possíveis que ela descreve. As relações hierárquicas que são designadas neste nível são: Conteúdo Proposicional (p), Episódios (ep), Estados-de-Coisas (e) e Propriedade Configuracional (f) ${ }^{10}$.

8 A formulação, na Gramática Discursivo-Funcional, se refere às regras que determinam quais representações pragmáticas e semânticas são válidas na linguagem. Essa operação leva em consideração três processos interligados (i) a seleção de estruturas apropriadas do NI e do NR; (ii) a inserção de lexemas apropriados dentro dessas estruturas; (iii) aplicação de operadores simbolizando as diferenças gramaticais requeridas na linguagem sob análise (HENGEVELD; MACKENZIE, 2008).

9 Falante e Ouvinte serão grafados com letra maiúscula quando se tratar de termos da GDF.

10 A Gramática Discursivo-Funcional é uma teoria funcionalista - derivada da Gramática Funcional de Dik (1997) - que, segundo Hengeveld e Mackenzie (2008), reflete o processamento linguístico, pois começa com a intenção do falante e acaba com a articulação de uma expressão linguística. Isso explica o porquê de sua organização hierarquicamente descendente. Apesar da rígida organização do modelo, não se trata de uma teoria formalista, uma vez que não limita o estudo linguístico à investigação de um sistema independente do uso da linguagem, tampouco está comprometida com a existência de estruturas mentais, cujos fundamentos são tipicamente considerados inatos. 
O Nível Morfossintático, por sua vez, trata dos aspectos estruturais de uma unidade linguística. Juntamente com o Nível Fonológico, ele cuida da codificação das distinções interpessoais e representacionais.

Já o Nível Fonológico, último proposto pela teoria, é responsável pela parte da codificação que não foi abrangida pelo Nível Morfossintático. Esse nível fornece um número de indicações, em cada camada, que o componente de saída converte em um resultado sonoro.

Interessa-nos o conceito de função retórica, que se relaciona aos modos como os componentes do discurso são ordenados e também às propriedades formais dos enunciados que influenciam o Ouvinte a aceitar tais propósitos. Como mencionado, a Concessão enquanto função retórica constitui uma maneira encontrada pelo Falante de conceder algo ao Ouvinte a fim de atingir algum objetivo conversacional, como em (2), extraído de Hengeveld e Mackenzie (2008, p. 54), em que o Falante afirma que o trabalho foi fácil, e, logo após, considerando seu Ouvinte, concede a informação que levou mais tempo que o esperado.

$$
\text { O trabalho foi fácil, embora tenha levado mais tempo que o esperado. }
$$

(Traduzido de Hengeveld e Mackenzie, 2008, p. 54)

Na GDF, a concepção de duas entidades ligadas por uma função ocorre quando tais entidades estabelecem entre si algum tipo de relação. No caso das funções retóricas essa relação é interpessoal, isto é, trata-se de uma estratégia comunicativa do falante. Quando a relação não ocorre no domínio interpessoal, mas sim representacional, configura função semântica, uma relação entre um núcleo e um dependente. As concessivas podem constituir também funções semânticas, quando se alinham ao esquema embora $p$, $q$, em que $p$ corresponde às tradicionais orações subordinadas e $q$, às principais. Interessa-nos, no presente estudo, as concessivas que constituem funções retóricas.

Assim como as concessivas, as condicionais também podem exercer função retórica ou semântica. Oliveira e Hirata-Vale (2016), ao descreverem a atuação das orações condicionais na língua portuguesa com base na GDF, reconhecem esses dois tipos de função. Interessa-nos, aqui, os casos de função semântica, os quais se alinham àqueles que se encaixam no esquema Se $p$, (então) $q$ (cf. NEVES, 2000), em que $p$ representa as orações condicionais e $q$, as principais, sendo, então, $p$ a condição para a realização de $q$.

Em vista do exposto, observa-se que, na GDF, tanto as relações concessivas quanto as condicionais podem constituir funções semânticas ou retóricas, a depender do domínio de atuação. 


\section{Operadores de ênfase}

Operadores são elementos de natureza gramatical que fornecem informações adicionais (opcionais) sobre o papel de uma variável no discurso. Uma característica importante dessa categoria, conforme aponta Keizer (2015), é que os operadores não podem receber modificação ou serem expandidos, sendo essa uma característica dos modificadores.

Um operador de ênfase é, portanto, um elemento de natureza gramatical opcional que assinala ênfase, sendo essa uma categoria pragmática muito importante no escopo da GDF. Trata-se, portanto, de uma instância gramaticalmente codificada que revela a intenção do Falante com relação ao Ato Discursivo que escopa. Aplicada a uma construção do espanhol encabeçada por incluso si, como em (3), tem o propósito de destacar a informação que segue:

(3) La situación, económicamente dramática para una población acogotada tras años de penuria, se ha hecho insostenible políticamente para los dirigentes de La Habana. Incluso si la aventura de los ciudadanos no termina como deseaban, esto es, con la obtención del asilo político, el daño al régimen ya está hecho. (1994, 5, Política)

A situação, economicamente dramática para uma população esgotada depois de anos de penúria, está insustentável politicamente para os dirigentes de La Habana. Mesmo se a aventura dos cidadãos não terminar como desejavam, isto é, com a obtenção do asilo político, o dano ao regime já está feito.

Nota-se em (3) que a função do operador de ênfase, conforme já propunha Keizer (2015) é a de providenciar informação adicional à oração seguinte, no caso, la aventura de los ciudadanos no termina como deseaban na medida em que destaca um conteúdo para a correta interpretação do ouvinte.

As construções com um operador enfático que pertencem à camada do Ato Discursivo são representadas da seguinte forma:

(emph $\left.A_{1}:\left[\left(F_{1}\right)\left(P_{1}\right)_{S}\left(P_{2}\right)_{A}\left(C_{1}\right)\right]^{A}\right)$

Na representação, a ênfase (emph) encabeça a estrutura no Nível Interpessoal, o que significa que os elementos gramaticais que desempenham papel enfático escopam todo o Ato Discursivo $\left(A_{1}\right)$ subsequente, que contém uma llocução $\left(F_{1}\right)$, Conteúdo Comunicado $\left(\mathrm{C}_{1}\right)$ e dois Participantes $\left(\mathrm{P}_{1}\right.$ e $\left.\mathrm{P}_{2}\right)$ : um Falante (Speaker) e um Ouvinte (Addressee). 


\section{As orações introduzidas por incluso si e a noção de escalaridade}

Incluso, para Flamenco García (1999), situa a expressão que escopa em um ponto determinado e, implicitamente, estabelece um contraste com outras expressões alternativas. A função desse elemento, para o autor, consiste em assinalar a presença de uma escala de natureza pragmática com relação ao contexto em que o enunciado ocorre. Uma escala linguística, segundo Flamenco García (1999), é um conjunto de elementos ou expressões contrastivas que podem se ordenar linearmente de maior para menor em virtude da sua força semântica ou do grau de informação que veiculam.

Incluso si, por sua vez, para Flamenco García, proporciona uma interpretação concessivocondicional quando o foco recai sobre toda a oração subordinada, conforme exemplo do autor em (4), e não apenas um elemento dessa oração, conforme exemplo do autor em (5), pois, nesse caso, a estrutura passa a expressar condicionalidade.

(4) Incluso si bebes una sola gota de alcohol en el trabajo, el jefe te despedirá. (FLAMENCO GARCÍA, 1999, p. 3845)

Mesmo se você beber uma só gota de álcool no trabalho, o chefe te despedirá.

(5) Si bebes incluso una sola gota de alcohol en el trabajo, el jefe te despedirá. (FLAMENCO GARCíA, 1999, p. 3845)

Se você beber mesmo uma só gota de álcool no trabalho, o chefe te despedirá.

Rodríguez Rosique (2012) não reconhece as orações introduzidas por incluso si exatamente como concessivo-condicionais. A autora propõe a existência de três tipos diferentes de orações introduzidas por incluso si e considera que a diferença entre eles depende do escopo de incluso e de questões discursivas e contextuais.

O primeiro tipo corresponde ao sentido condicional com força argumentativa. Rodríguez Rosique (2012) afirma que, nesse caso, incluso implica que uma proposição é mais informativa do que outra, que é contextualmente acessível. O propósito de incluso é interagir com si e conectar sentenças favorecendo a mesma conclusão, como representa (6).

(6) La primera medida fundamental, tenga el enfermo una u otra edad, y sea la hemorragia más o menos voluminosa, es el reposo absoluto en cama. Si existen fenómenos de defectuosa irrigación cerebral, se colocarán las extremidades inferiores en un plano más alto, e incluso si fuera preciso se ligarán transitoriamente. (RODRÍGUEZ ROSIQUE, 2012, p. 103) 
A primeira medida fundamental, tenha o doente uma idade ou outra, e seja a hemorragia mais ou menos volumosa, é o repouso absoluto na cama. Se existirem fenômenos de irrigação cerebral defeituosa, as extremidades inferiores serão colocadas em um plano mais alto, e mesmo se for preciso, se ligarão transitoriamente.

Rodríguez Rosique (2012) aponta que, nesse tipo de construção, incluso funciona como marca discursiva, status demonstrado pela possibilidade de ser substituído por outra marca discursiva similar, como es más. Ao mesmo tempo, incluso admite uma conjunção precedente, como y (conjunção aditiva, correspondente a e em português), conforme comprova (7) a seguir:

(7) Si existen fenómenos de defectuosa irrigación cerebral, se colocarán las extremidades inferiores en un plano más alto, y, es más, si fuera preciso se ligarán transitoriamente. (RODRÍGUEZ ROSIQUE, 2012, p. 105)

Se existirem fenômenos de irrigação cerebral defeituosa, as extremidades inferiores serão colocadas em um plano mais alto, e, além disso, se for preciso, se ligarão transitoriamente.

Uma reinterpretação desse caso permite considerar que a função de incluso em (8) é chamar a atenção para a pior das hipóteses apresentada pelo falante, que é a necessidade de se relacionar transitoriamente. Vale a pena ressaltar que o exemplo apresenta uma sequência de hipóteses: si existen fenómenos.... se colocarán las extremidades, si fuera preciso... se ligarán transitoriamente, o que justifica a classificação condicional com força argumentativa.

O segundo tipo proposto pela autora diz respeito às construções que se aproximam das concessivas prototípicas. Como ocorre com o caso anterior, a oração introduzida por incluso veicula uma informação mais importante e representa um argumento mais forte para uma conclusão contextual implícita ou explícita. Segundo a autora, nesses casos, a estrutura condicional parece argumentar em favor de uma verdade mais geral que é acessível no discurso. Para ela, essas estruturas são conhecidas por engatilhar um sentido concessivo, como mostra (8) a seguir.

(8) Parece ser que tomar un suplemento de ácido fólico antes del embarazo es bastante preventivo e incluso si se toma después de haber detectado espina bífida en el feto, reduce la gravedad de la lesión. (RODRÍGUEZ ROSIQUE, 2012, p. 106).

Parece que tomar um suplemento de ácido fólico antes da gravidez é bastante preventivo e, mesmo se se tomar depois de haver detectado espinha bífida no feto, reduz a gravidade da lesão. 
Ao contrário do primeiro grupo, ainda para Rodríguez Rosique (2012), essas estruturas podem desencadear um sentido contrastivo, comprovado em (9) a seguir pela possível paráfrase de aunque + subjuntivo:

(9) Aunque se tome después de haber detectado espina bífida en el feto, reduce la gravedad de la lesión. (RODRÍGUEZ ROSIQUE, 2012, p. 107)

Ainda que se tome depois de haver detectado espinha bífida no feto, reduz-se a gravidade da lesão.

Para a autora, o sentido contrastivo é gerado pela interação entre incluso e seu escopo, que é um constituinte da oração subordinada (después), conforme mostra a possível mobilidade de incluso na construção: y si se toma incluso después de haber detectado espina bífida en el feto, reduce la gravedad de la lesión.

O terceiro e último tipo considerado por Rodríguez Rosique (2012) diz respeito a incluso si concessivo-condicional. Segundo ela, há dois tipos de incluso si concessivo-condicional: de sentido polar e de sentido universal.

No que diz respeito ao primeiro tipo, o de sentido polar, incluso não precede mais uma condição suficiente, isto é, nesse caso, a oração principal não resiste por causa da oração subordinada, mas apesar dela. O significado dessa estrutura é contrastivo, sendo possível a paráfrase de aunque + subjuntivo, como representa (10) e sua paráfrase em (10a).

(10) [...] Si Gonzallo me ha llamado, por algo será. Yo vendré siempre que él quiera verme, incluso si eso pone en riesgo mi matrimonio. (RODRÍGUEZ ROSIQUE, 2012, p. 109)

[...] Se Conzallo me chamou, por alguma coisa será. Eu virei sempre que ele quiser me ver, mesmo se isso puser em risco meu casamento.

(10a) (10a) Yo vendré siempre que él quiera verme, aunque eso ponga en riesgo mi matrimonio. Eu virei sempre que ele queira me ver, mesmo que isso coloque meu casamento em risco.

No que diz respeito ao caso de incluso si de sentido universal, Rodríguez Rosique considera que, em alguns casos, incluso não é o único responsável pela ideia de escalaridade. Embora consiga fazer isso sozinho, há informações contextuais, como o superlativo por exemplo, que focalizam o extremo de uma escala, como apresenta (11) a seguir. 
(11) En España, una mujer futbolista, internacional absoluta, incluso si fuera considerada la mejor jugadora del mundo, siempre partiría con desventaja frente a sus colegas internacionales masculinos en la carrera hacia el título de entrenador nacional. (RODRÍGUEZ ROSIQUE, 2012, p.113)

$\mathrm{Na}$ Espanha, uma mulher futebolista, absolutamente internacional, mesmo se fosse considerada a melhor jogadora do mundo, sempre partiria com desvantagem em relação a seus colegas internacionais masculinos na carreira até o título de treinador nacional

Nesses casos, a oração subordinada denota um parâmetro completo e focaliza o extremo de uma escala. Curiosamente, no entanto, o valor universal não é engatilhado por incluso, mas pelo superlativo la mejor jugadora del mundo.

Em síntese, para Rodríguez Rosique(2012), o sentido condicional das orações introduzidas por incluso si sempre está presente, em maior ou menor grau, independente da presença de um valor contrastivo entre oração subordinada e oração principal.

\section{Análise e discussão dos resultados}

Nossas análises revelam que as orações introduzidas por incluso si no espanhol escrito exibem relações de três tipos distintos ${ }^{11}$ : uma relação entre proposições, entre atos de fala (cf. SWEETSER, 1990) e de porções textuais (cf. STASSI-SÉ, 2012).

\section{Incluso si entre proposições}

As orações desse tipo apresentam entre si uma relação que se refere aos traços semânticos da unidade linguística, uma vez que o vínculo entre oração principal e subordinada envolve relações que não podem ser localizadas no tempo e no espaço, mas sim concebidas na mente do Falante, conforme representa (12):

(12) Ayer terminaron los ensayos, a lo largo de los cuales Indurain ha rodado en tiempos de récord, pero sin superar jamás los 18 minutos de esfuerzo continuado. El objetivo marcado claramente por el equipo que dirige José Miguel Echavarri es batir "aunque sea por un metro" la marca de Obree. "Incluso si sólo superamos el anterior récord de Boardman (52,270) ya nos daríamos por satisfechos". (1994, 4, Deporte)

11 Destacamos que o percurso desta análise não será guiado pela organização descendente da GDF, já que, por fins didáticos, optamos por iniciar a descrição pelo tipo oracional que coincide com o comumente apresentado nos compêndios descritivos do espanhol. (cf. FLAMENCO GARCÍA, 1999). 
Ontem os ensaios terminaram, durante os quais Indurain disparou em tempo recorde, mas nunca ultrapassou 18 minutos de esforço contínuo. O objetivo claramente marcado pela equipe liderada por José Miguel Echavarri é bater "mesmo que por um metro" a marca Obree. "Inclusive se apenas ultrapassarmos o recorde anterior do Boardman (52.270), já nos daríamos por satisfeitos".

Em (12), o falante apresenta um julgamento sobre sua atitude na oração subordinada (superar o recorde anterior de Boardman) e apresenta uma conclusão, com base em premissas, na oração principal (ya nos daríamos por satisfechos). Na perspectiva da Gramática Discursivo-Funcional, essas relações são concebidas na camada do Conteúdo Proposicional, camada mais alta do Nível Representacional, pois trata-se de construtos mentais e julgamentos que passam pelo crivo do Falante. Nos dados, essas relações são encontradas em 54 ocorrências, responsáveis por 78\% do total.

Conteúdos Proposicionais, segundo Hengeveld e Mackenzie (2008), estão relacionados à especificação de atitude proposicional, como certeza, dúvida ou descrença. Esse estatuto pode ser comprovado por meio de alguns testes, como a inserção dos modificadores efectivamente e probablemente, que indicam certeza ou dúvida, respectivamente. Dessa forma, a natureza epistêmica das ocorrências pode ser avaliada, conforme é possível notar em (12a) e em (12b) a seguir, que apresentam a inserção de modificadores na oração subordinada e na oração principal respectivamente.

(12a) Incluso si probablemente/efectivamente sólo superamos el anterior récord de Boardman $(52,270)$ ya nos daríamos por satisfechos.

(12b) Incluso si sólo superamos el anterior récord de Boardman (52,270) probablemente/ efectivamente ya nos daríamos por satisfechos.

Não é difícil reconhecer que esses casos coincidem com aqueles postulados por Rodríguez Rosique (2012) como condicional com força argumentativa, em que incluso atua como uma marca discursiva (termos da autora) e pode ocorrer em outras posições na oração.

O teste da retirada de incluso mostra que o que se perde é, na verdade, "a marca discursiva", a noção de ênfase que essa partícula veicula sobre a hipótese apresentada pelo Conteúdo Proposicional. Essa hipótese é codificada no domínio morfossintático pela conjunção si, como se comprova em (12d) a seguir, em que a mudança da posição de incluso altera também seu escopo, que passa a enfatizar uma parte ou um único elemento da oração e não mais recai sobre a hipótese codificada por si. 
(12d) Si sólo superamos incluso el anterior récord de Boardman (52,270), ya nos daríamos por satisfechos.

Em (12d) observamos que incluso passa a enfatizar el anterior récord de Boardman, o que mostra que essa partícula não precisa ocorrer necessariamente ao lado de si quando da atuação dessas construções no Nível Representacional, pois, nesse caso, o que há é a veiculação de uma hipótese e uma conclusão, o que nos permite dizer que se trata, no âmbito da GDF, de função semântica condição. Essa função, observada por Oliveira e Hirata-Vale (2016) na expressão das condicionais em português, pode ser alinhada ao esquema Se p, (então) q; em outras palavras, em espanhol, Si p (superar é récord), q (darnos por satisfechos).

Funções semânticas, de acordo com Hengeveld e Mackenzie (2008), como já mencionado, especificam uma relação entre um núcleo e um dependente. Ao representar essa relação, atribuem-se funções semânticas ao dependente, conforme representado em (12e):

(12e) $\quad\left[\left(p_{i}:-\right.\right.$ ya nos daríamos por satisfechos - $\left(p_{i}\right):\left(p_{j}:-\right.$ sólo superamos el anterior récord de Boardman $\left.\left.-\left(p_{j}\right)\right)_{\text {Cond }}\left(p_{i}\right)\right]$

Em (12e), o Conteúdo Proposicional ya nos daríamos por satisfechos é representado por $\left(\mathrm{p}_{\mathrm{i}}\right)$ e o Conteúdo Proposicional sólo superamos el anterior récord de Boardman é representado por $\left(p_{j}\right)$. Nesse caso, $\left(p_{j}\right)$ atua como modificador de $\left(p_{\mathrm{i}}\right)$, recebendo a função semântica de Condição (cond $)$. O Conteúdo Proposicional descrito em $\left(\mathrm{p}_{\mathrm{j}}\right)$ é localizado dentro do escopo do Conteúdo Proposicional principal $\left(\mathrm{p}_{\mathrm{i}}\right)$.

Vale ressaltar que, na representação, a conjunção si não é considerada, pois, como já afırmado, é responsável por assinalar a relação de condição no processo de codificação no Nível Morfossintático, onde se reconhece a relação de subordinação.

Essa relação perpassa as três camadas abaixo da Expressão Linguística (Le), portanto, as camadas da Oração $(\mathrm{Cl})$, do Sintagma $(\mathrm{Xp})$ e da Palavra $(\mathrm{Xw})$. Em uma relação de subordinação, Orações podem ocorrer como constituintes de outras Orações, desempenhando papel de Orações adverbiais, complementares ou predicativas.

\section{Incluso si entre atos de fala}

O segundo tipo de oração prefaciada por incluso si detectado em nossos dados pode ser observado em (13) a seguir: 
(13) [...] marcaría el número. Esperaría a oír su voz. Estoy seguro de que su voz la reconocería inmediatamente. Incluso si se ha vuelto borracha y fumadora. Aun así la reconocería. $(1995,79$, Novela)

[...] marcaria o número. Esperaria ouvir sua voz. Tenho certeza de que sua voz reconheceria imediatamente. Mesmo se se tornou alcoólatra e fumante. Ainda assim a reconheceria.

Percebe-se que a oração incluso si se ha vuelto borracha y fumadora acrescenta uma informação nova ao que foi dito anteriormente; trata-se, na verdade, de uma ressalva feita pelo escrevente a fim de justificar a oração principal anterior estoy seguro de que su voz la reconocería imediatamente, o que coincide com o que Chafe (1984) denomina aftherthough, um "adendo" em que o Falante adiciona um comentário ao que foi dito anteriormente.

Esse tipo de relação caracteriza, na Gramática Discursivo-Funcional, uma relação estabelecida entre dois Atos Discursivos, caso reconhecido em 11 ocorrências, responsáveis por $16 \%$ do total. O primeiro Ato Discursivo é estoy seguro de que su voz la reconocería inmediatamente, e o segundo, se ha vuelto borracha y fumadora. Os Atos Discursivos, segunda camada mais alta do Nível Interpessoal, segundo Kroon (1995) consistem nas menores unidades identificáveis do comportamento comunicativo.

Em uma relação desse tipo, o primeiro Ato Discursivo é o Nuclear (Ai), e o segundo, o subsidiário (Aj), que carrega a função retórica. Aqui, o que está em jogo na comunicação é a intenção do Falante e, a partir dessa intenção, ele vale-se de estratégias comunicativas para chegar ao seu propósito na interação. A estratégia do Falante, nesse caso, é acrescentar uma ressalva com relação ao que foi dito no primeiro Ato, o que configura a função retórica Concessão. Pode-se comprovar que se trata de função retórica Concessão também ao atentar-se para o contexto que segue, aun así la reconocería (mesmo assim eu a reconheceria), uma reformulação claramente concessiva de tudo o que foi dito: eu reconheceria sua voz de qualquer maneira, até mesmo na pior das possibilidades, se ela tivesse se tornado bêbada e fumante, já que, as informações advindas do Componente Contextual permitem que o Ouvinte infira que os bêbados e os fumantes apresentam alterações na voz.

Segundo Hengeveld e Mackenzie (2008), a função retórica Concessão corresponde a uma estratégia do falante para chegar a determinado propósito comunicativo, seja o de fazer uma ressalva ou propor uma explicação, justificativa para o Ato Subsidiário enunciado anteriormente, a fim de conceder algo, conforme podemos observar na ocorrência (14): 
(14) En Fina hay algo de cazadora, de animal de presa, puedes asegurarlo, aunque yo pienso que lo que le pasa, lo de veras preocupante en ella, es que se lanzó muy niña al arroyo. La calle no es fácil. Sí, no es necesario que pongas esa cara. Tiene un niño. Es normal, ¿no? La gente sólo opina si nos ocurre a personas como nosotras. Pero joder y tener un hijo es normal, ¿verdad? Incluso si tomas precauciones... Por eso todo es una mierda, amigo mío. Ocurre, es voluntad de Dios. (1991, 77, Novela)

Na Fina há algo de caçador, de animal de presa, pode assegurar, embora eu pense que o que passa, o que de verdade é preocupante nela é que se lançou muito nova ao ambiente de marginalização. A rua não é fácil. Sim, não é necessário que faça essa cara. Tem um filho. É normal, não? As pessoas só opinam se acontecer com pessoas como a gente. Mas transar e ter um filho é normal, não é? Mesmo se você tomar precaução...por isso tudo é uma merda, meu amigo. Acontece, é vontade de Deus.

Em (14), observamos que o Ato Subsidiário Incluso si tomas precauciones veicula um matiz hipotético (pode-se ou não tomar precauções) e antecipa possíveis objeções do Ouvinte. A oração prefaciada por incluso si adiciona uma informação nova e não esperada ao Ato Discursivo Subsidiário joder y tener un hijo es normal, pois insere uma observação ao que foi dito antes, ou seja, o Falante concede um fato ao Ouvinte, algo que poderia ser usado por seu interlocutor como objeções.

O Falante pode ter muitas intenções ao fazer uma ressalva. De modo geral, essa característica se relaciona à tentativa de preservação de face, isto é, o locutor antecipa uma possível conclusão do interlocutor e insere o Ato Discursivo que contém a função retórica para justificar o Ato enunciado anteriormente que pode levar o interlocutor a essa conclusão não desejada. Assim, em outras palavras, podemos dizer que a ressalva é uma estratégia utilizada pelo Falante que busca evitar interpretações equivocadas e possíveis objeções por parte do interlocutor.

As construções desse tipo assemelham-se às que a autora classifica como concessivocondicional com sentido contrastivo em que é evidente o sentido concessivo, o que permite que incluso si seja substituído por aunque + subjuntivo (embora + subjuntivo), conforme mostra a paráfrase (14a), em que se observa a conjunção aunque acompanhada do verbo tomar no subjuntivo (tomes):

(14a) La gente sólo opina si nos ocurre a personas como nosotras. Pero joder y tener un hijo es normal, ¿verdad? Aunque tomes precauciones...

Para avaliar a natureza dos Atos Discursivos que desempenham função retórica Concessão, Hengeveld e Mackenzie (2008, p. 55), admitem a possibilidade de inserir yo admito/admita que (I conced that) no Ato Subsidiário, conforme (14b). Uma vez que essa 
inserção é possível e não altera o sentido da construção, o que confirma a relação de concessão entre Atos Discursivos.

(14b) Pero joder y tener un hijo es normal, ¿verdad? Incluso si yo admito/a que tomas precauciones.

O teste realizado em (14b) comprova que é possível a inserção do ato performativo yo admito/a que no Ato Discursivo Incluso si tomas precauciones, o que comprova caráter interpessoal desse tipo de construção.

Esse Ato Discursivo, como vimos, é Subsidiário $\left(A_{\jmath}\right)$ com relação ao Ato Nuclear $\left(A_{1}\right)$. Nessa relação, é o Ato Subsidiário que carrega a função retórica (Conc), conforme se verifica na representação a seguir:

$(14 \mathrm{C}) \quad\left[\left(A_{i}\right.\right.$ : - joder y tener un hijo es normal $\left.\left.-\left(A_{f}\right)\right)\left(A_{j} \text { : - tomas precauciones }-\left(A_{J}\right)\right)_{\text {cond }}\right]$

Na representação, os Atos Discursivos são dispostos na ordem em que eles se realizam. Por essa razão, o Ato Nuclear, representado por $\left(A_{1}\right)$, é apresentado antes do Ato Subsidiário, representado por $\left(A_{\jmath}\right)$. A função retórica de Concessão (Conc) recai, como vimos, sobre o Ato Subsidiário, que expressa uma ressalva à enunciação do que foi dito no Ato Nuclear.

Percebe-se que incluso si tomas precauciones é dependente da unidade joder y tener un hijo es normal, enquanto esta última poderia ser usada de forma independente. Na perspectiva da GDF, essa relação, no Nível Morfossintático, engendra o processo da cossubordinação, em que uma das Orações não poderia ocorrer por si só, enquanto a outra, sim. Assim, a Oração joder y tener un hijo es normal pode ocorrer de forma independente e a oração Tomas precauciones não pode, pois depende da primeira.

\section{Incluso si entre porções textuais}

O terceiro tipo de oração detectado em nossos dados diz respeito a orações que não se subordinam sintática e semanticamente a outra oração, conforme representa (15) a seguir.

British Airways firmó un acuerdo en julio pasado en el que se comprometía a decidir antes de fin de año si compraba una parte del capital de Iberia. ¿Sigue en pie esa fecha? 
- Sí. Estamos esperando la información que nos tienen que dar Sepi e Iberia para que evaluemos la situación. Pero nuestra intención es poder llegar a una conclusión antes de fin de año.

- ¿Incluso si la alianza entre British y American Airlines para esa fecha aún no se ha resuelto en Bruselas?

- Incluso. Continuaremos la evaluación independientemente de cómo esté el proceso de la alianza (1997, 8, Negocios)

- British Airways assinou um acordo em julho do mês passado no qual se comprometia a decidir antes do fim do ano se comprava uma parte do capital da Iberia. Continua de pé essa data?

- Sim. Estamos esperando a informação que Sepi e Iberia tem que dar para que avaliemos a situação. Mas nossa intenção é poder chegar a uma conclusão antes do fim do ano.

- Mesmo se a aliança entre British y American Airlines para essa data ainda não tenha se resolvido em Bruxelas?

- Mesmo. Continuaremos a avaliação independentemente de como esteja o processo da aliança.

Observamos em (15) que a oração prefaciada por incluso si tem a função de impulsionar o discurso, uma vez que constitui uma reação do interlocutor por meio de uma pergunta. Assim, Incluso si la alianza entre British y American Airlines para esa fecha aún no se ha resuelto en Bruselas pode ser considerado um lance na interação, o que caracteriza, na GDF, um Movimento, maior camada do Nível Interpessoal, responsável por 4 ocorrências, o que corresponde a $6 \%$ do total.

Esse Movimento, por sua vez, é constituído por um único Ato Discursivo, com Ilocução interrogativa e se refere a todo o contexto imediatamente anterior [...] estamos esperando la información que nos tienen que dar Sepi e Iberia para que evaluemos la situación. Pero nuestra intención es poder llegar a una conclusión antes de fin de año, o qual, por também representar um lance na interação, constitui igualmente um Movimento, mas constituído por mais de um Ato Discursivo.

Stassi-Sé (2012) afirma que orações adverbiais que iniciam Movimentos representam funções que dizem respeito a diferentes contribuições que essas estruturas podem trazer ao discurso, pois indicam o tipo de avanço na interação. Tendo isso em vista, a autora propõe a função interacional como um tipo de função discursiva típica entre Movimentos. 
Ela postula ainda, para as concessivas, a função interacional Adendo, representando aspectos discursivos das unidades linguísticas que se relacionam ao papel de adicionar informação nova no discurso, ou, em outros termos, essa função constitui um adendo a uma informação anteriormente expressa no discurso.

Embora não seja o tipo de oração mais frequente, as estruturas prefaciadas por incluso si exercem essa função, pois introduzem uma informação contrária e hipotética ao que estava sendo dito, como já apresentado em (16), representado a seguir em (16a):

(16a) ( $\mathrm{M}_{1}$ : - Estamos esperando la información que nos tienen que dar Sepi e Iberia para que evaluemos la situación. Pero nuestra intención es poder llegar a una conclusión antes de fin de año - $\left.\left(M_{1}\right)\right)$ : $\left(M_{j}\right.$ : - la alianza entre British y American Airlines para esa fecha aún no se ha resuelto en Bruselas $\left.\left.-\left(\mathrm{M}_{\mathrm{J}}\right)\right)_{\text {ADENDO}}\right)$

Em (16a), o Movimento Subsidiário (M $M_{\jmath}$ exerce a função interacional Adendo em relação ao Movimento Nuclear $\left(\mathrm{M}_{1}\right)$ e incluso si é inserido no Nível Morfossintático para codificar a função interacional.

Não é difícil reconhecer que esse caso coincide com o terceiro tipo postulado por Rodríguez Rosique (2012, p. 108), em que, para a autora, incluso atua como um contraargumentador (nos termos da autora), pois indica "que a informação que introduz é mais informativa do que proposicional". Argumenta a pesquisadora ainda que, nesses casos, incluso deixa de veicular escalaridade e passa a fazer parte do discurso (nos termos da autora), o que confirma o funcionamento interpessoal desses casos.

Nesse sentido, podemos dizer que incluso incide sobre o Conteúdo Comunicado do Ato Discursivo que compõe o Movimento, por isso é fundamental no contexto e pode, inclusive, apresentar funcionamento autônomo, como comprova o trecho que segue a pergunta do documentador, repetido em por conveniência em (16c) a seguir:

(16c) - ¿Incluso si la alianza entre British y American Airlines para esa fecha aún no se ha resuelto en Bruselas?

-Incluso. Continuaremos la evaluación independientemente de cómo esté el proceso de la alianza.

Pode-se dizer, em resumo, que aqui incluso tem a função escalar e enfática, que, juntamente com a conjunção si, adiciona uma hipótese que contrasta com todo o contexto anterior. 
Os resultados mostram que a maioria dos casos (78,3\%) concentra-se na camada do Conteúdo Proposicional, a mais alta do Nível Representacional, único caso apresentado pelos compêndios descritivos do espanhol (cf. FLAMENCO GARCÍA, 1999). Não deixam de ser significativos, no entanto, os números encontrados na camada do Ato Discursivo (16\%) e, em menor escala, na camada do Movimento (5,7\%), as quais, juntas (21,7\%) representam a atuação dessas construções no Nível Interpessoal.

\section{Conclusões}

Tendo como fator norteador as camadas de organização da GDF, constatamos que essas construções podem ser de três tipos diferentes, contrariamente ao que propõe os compêndios descritivistas do espanhol que apresentam apenas um tipo de oração prefaciada por incluso si. Nossos dados revelam a incidência dessas orações não apenas no nível semântico, único considerado pelas gramáticas descritivistas, mas também no nível pragmático, quando atuam como estratégia retórica ou interacional.

No que diz respeito ao primeiro tipo de orações prefaciadas por incluso si, as que se estabelecem na camada do Conteúdo Proposicional (78\%), os dados mostram que desempenham função semântica condição. Nessa camada, constatamos que incluso interage com a conjunção condicional prototípica do espanhol si e tem o papel de enfatizar a hipótese codificada por essa conjunção. Como um elemento focal, incluso não tem a obrigatoriedade de acompanhar a conjunção si e pode incidir sobre outros termos da oração. Nesse caso, diferentemente do que considera Montolío (1999), incluso si não constitui um bloco indissociável.

Quanto ao segundo tipo, as que ocorrem entre Atos Discursivos (16\%) desempenham função retórica Concessão. Nesse caso, do ponto de vista da interação, sem a partícula incluso, a informação inserida pelo Falante a fim de guiar seu Ouvinte não é aceitável, o que se explica porque incluso introduz uma informação que é comunicativamente relevante. Dito de outro modo, nas orações que se estabelecem entre Atos Discursivos, incluso enfatiza o Conteúdo Comunicado do Ato Discursivo Subsidiário, sendo imprescindível no contexto.

O terceiro e último tipo estabelece-se entre Movimentos (6\%) e desempenha a função interacional Adendo. Assim como no segundo caso, incluso tem o papel de enfatizar a informação que virá em seguida, a qual constitui um possível obstáculo de uma escala de possibilidades. Neste caso, incluso também é imprescindível para o contexto.

Nossos resultados mostram, portanto, que as orações prefaciadas por incluso si podem se estabelecer nas camadas mais altas do Nível Interpessoal, Movimento e Ato Discursivo, quando desempenham, respectivamente, função interacional adendo e função retórica 
concessão. Estabelecem-se ainda na camada mais alta do Nível Representacional, Conteúdo Proposicional, quando desempenham função semântica concessão.

Os resultados mostram que, apesar de incluso si ser apresentado na literatura como uma locução conjuntiva que introduz orações híbridas que mesclam características tanto das concessivas quanto das condicionais, sob o escopo da GDF constatamos que essas construções são concebidas de forma discreta, em termos de funções, um conceito necessariamente relacional, sendo elas: função interacional adendo, função retórica concessão e função semântica condição, a depender das intenções comunicativas do falante.

\section{Agradecimentos}

Esta pesquisa teve apoio da FAPESP (Processo 2016/01435-9), a quem agradecemos.

\section{REFERÊNCIAS}

CHAFE, W. L. How People Use Adverbial Clauses. Annual Meeting of the Berkely Linguistic Society, v. 10, p. 437-449, 1984.

CREVELS, M. Concession in Spanish. In: BOLKESTEIN, A. M.; HANNAY, M. (ed.). Functional grammar and verbal interaction. Amsterdam: John Benjamins, 1998. p. 129148.

FLAMENCO GARCÍA, L. Las construcciones concesivas y adversativas. In: BOSQUE, I.; DEMONTE, V. (org.). Gramática descriptiva de la lengua española. Madrid: Espasa-Calpe, v. 3: Entre la oración y el discurso, 1999. p. 3805-3878.

GARCIA, T. S. Orações concessivas independentes à luz da gramática discursivo-funcional. Alfa, São José do Rio Preto, p. 475-494, 2013.

HASPELMATH, M.; KÖNIG, E. Concessive conditionals in the languages of Europe. In: VAN DER AUWERA, J. Adverbial constructions in the languages of Europe. New York: Mouton de Gruyter, 1998. p. 335-419.

HENGEVELD, K. Adverbial Clauses in the languages of Europe. In: VAN DER AUWERA, J. (ed.). Adverbial constructions in the language of Europe. Berlin: Mouton de Gruyter, 1998. p. 335-419. 
HENGEVELD, K.; MACKENZIE, J. L. Gramática Discursivo-Funcional. In: SOUSA, E. F. (org.). Funcionalismo linguístico: novas tendências teóricas. Tradução Marize Dall'Aglio Hattnher. São Paulo: Contexto, 2012. p. 43-82.

HENGEVELD, K.; MACKENZIE, L. Functional Discourse Grammar: a typologically-based theory of language structure. Oxford: University Press, 2008.

KEIZER, E. A functional Discourse Grammar for English. Oxford: University Press, 2015.

KÖNIG, E. Concessive clauses. In: ASHER R. E. (ed.). The encyclopedia of language and linguistics. Oxford: Pergamon, 1994. p. 679-681.

KÖNIG, E. On the history of concessive connectives in English, diachronic and synchronic evidence. Lingua, Amsterdam, v. 66, n. 1, p. 1-19, 1985.

KÖNIG, E. Conditionals, concessive conditionals and concessives: areas of contrast, overlap and neutralization. In: TRAUGOTT, E. et al. (ed.). On conditionals. Cambridge: Cambridge University Press, 1986. p. 229-246.

KROON, C. Discourse Particles in Latin (Amsterdam Studies in Classical Philology 4). Amsterdam: Gieben, 1995.

MONTOLÍO, E. Las construcciones condicionales In: BOSQUE, I.; DEMONTE, V. (org.). Gramática descriptiva de la lengua española. Madrid: Espasa-Calpe, v. 3: Entre la oración y el discurso, 1999. p. 3642-3737.

MIZUNO, Y. Although Clauses in English Discourse: a functional analysis. 2007. Tese (Doutorado em Letras) - The Graduate School of Letters, Universidade de Hokkaido, Osaka, 2007.

NEVES, M. H. M. Gramática de usos do português. São Paulo: UNESP, 2000.

NEVES, M. H. M. construções concessivas. In: NEVES, M. H. M. (org.). Gramática do português falado. São Paulo: Humanitas/FFLCH/USP; Campinas: Editora da UNICAMP, v. 7: Novos estudos, 1999. p. 545-591.

OLIVEIRA, T. P. As conjunções e orações condicionais no português do Brasil. 2008. Tese (Doutorado em Linguística e Língua Portuguesa) - Faculdade de Ciências e Letras, Universidade Estadual Paulista "Júlio de Mesquita Filho", Araraquara, 2008. 
OLIVEIRA, T. P.; HIRATA-VALE, F. B. M. Orações condicionais no português: uma análise à luz da Gramática Discursivo-Funcional. In: OLIVEIRA, M. R.; CEZARIO, M. M. Funcionalismo linguístico: diálogos e vertentes. Rio de Janeiro: EDUFF, 2016. p. 185-204.

OLIVEIRA, T. P.; HIRATA-VALE, F. B. M. As conjunções condicionais na Gramática Discursivo Funcional. In: SOUZA, E. R. F. Funcionalismo linguístico. Análise e descrição. São Paulo: Contexto, 2012. p. 119-146.

PEZATTI, E. G.; CAMACHO, R. G. Funções retóricas e ordem: relação entre pragmática e morfossintaxe. In: RIOS, M.; CEZARIO, M. M. (org.). Funcionalismo linguístico: diálogos e vertentes. v. 40. Niterói: EDUFF, 2017. p. 157-184.

REAL ACADEMIA ESPAÑOLA: Banco de datos (CREA) [en línea]. Corpus de referencia del español actual. Disponível em: http://www.rae.es. Acesso em: 15 jan. 2017.

RODRÍGUEZ ROSIQUE, S. R. From discourse to grammar: when the Spanish incluso meets a si conditional. Lingvistica e Investigationes, John Benjamins Publishing Company, p. 94-119, 2012..

ROSÁRIO, I. C. Expressão da Concessividade em construções do português do Brasil. 2012. Tese (Doutorado em Língua Portuguesa) - Faculdade de Letras, Universidade Federal do Rio de Janeiro, Rio de Janeiro, 2012.

STASSI-SÉ, J. C. Subordinação discursiva no português à luz da gramática discursivo funcional. 2012. Tese (Doutorado em Estudos Linguísticos) - Instituto de Biociências, Letras e Ciências Exatas, Universidade Estadual Paulista "Júlio de Mesquita Filho", São José do Rio Preto, 2012.

SWEETSER, E. From Etymology to Pragmatics: Metaphorical and Cultural Aspects of Semantic Structure (Cambridge Studies in Linguistics). Cambridge: Cambridge University Press, 1990.

ZAMPRONEO, S. A Hipotaxe Adverbial Concessiva no Português Escrito Contemporâneo do Brasil. 1998. Dissertação (Mestrado em Linguística e Língua Portuguesa) - Faculdade de Ciências e Letras, Universidade Estadual Paulista "Júlio de Mesquita Filho", Araraquara, 1998. 